\title{
Effect of exercise on cognitive function in chronic disease patients: a meta-analysis and systematic review of randomized controlled trials
}

This article was published in the following Dove Press journal:

Clinical Interventions in Aging

II May 2017

Number of times this article has been viewed

\section{Hong Cai* \\ Guichen Li* \\ Shanshan Hua \\ Yufei Liu \\ Li Chen}

School of Nursing, Jilin University, Changchun, Jilin, People's

Republic of China

*These authors contributed equally to this work
Correspondence: Li Chen

School of Nursing, Jilin University, No 965 Xinjiang Street, Changchun, Jilin I3002I, People's Republic of China Tel/fax +8643185619366 Email chen_care@।26.com
Background: The purpose of this study was to conduct a meta-analysis and systematic review to assess the effect of exercise on cognitive function in people with chronic diseases.

Methods: PubMed, Web of Science, Embase, the Cochrane Library, CINAHL, PsycINFO, and three Chinese databases were electronically searched for papers that were published until September 2016. This meta-analysis and systematic review included randomized controlled trials that evaluated the effect of exercise on cognitive function compared with control group for people with chronic diseases.

Results: Totally, 35 studies met the inclusion criteria, with 3,113 participants. The main analysis revealed a positive overall random effect of exercise intervention on cognitive function in patients with chronic diseases. The secondary analysis revealed that aerobic exercise interventions and aerobic included exercise interventions had a positive effect on cognition in patients with chronic diseases. The intervention offering low frequency had a positive effect on cognitive function in patients with chronic diseases. Finally, we found that interventions offered at both low exercise intensity and moderate exercise intensity had a positive effect on cognitive function in patients with chronic diseases. The secondary analysis also revealed that exercise interventions were beneficial in Alzheimer's disease patients when grouped by disease type.

Conclusion: This meta-analysis and systematic review suggests that exercise interventions positively influence cognitive function in patients with chronic diseases. Beneficial effect was independent of the type of disease, type of exercise, frequency, and the intensity of the exercise intervention.

Keywords: exercise, cognitive function, physical activity

\section{Abbreviations}

ACE-R, Addenbrooke's Cognitive Examination-Revised; ADAS-Cog, Alzheimer's Disease Assessment Scale-cognitive subscale; AIDS, acquired immune deficiency syndrome; BCPT-cog, Breast Cancer Prevention Trial symptom checklist-cognitive problems scale; BDI-cog, Beck Depression Inventory-cognitive subscale; BDNF, brain-derived neurotrophic factor; BOPI-cog, Breast Cancer Prevention Trial Symptom Checklist-Cognitive Problems Scale; CDT, clock drawing test; CI, confidence interval; CINAHL, Cumulative Index to Nursing and Health Literature; CNKI, China National Knowledge Infrastructure; EORTC-cog, European Organization for Research and Treatment of Cancer-cognitive; ERFC, Rapid Evaluation of Cognitive Function; FAB, Frontal Assessment Battery; FACS, functional assessment of communication skills; $\mathrm{HR}_{\max }$, maximum heart rate; MCI, mild cognitive impairment; IL, interleukin; MD, mean difference; MMSE, Mini-Mental State Examination; MoCA, Montreal Cognitive 
Assessment; PFS-cog, Piper Fatigue Scale-cognitive; PRISMA, Preferred Reporting Items for Systematic Reviews and Meta-Analyses; SLCT, six-letter cancellation test; SMD, standardized mean difference; TCD, total cognitive domain; TNF- $\alpha$, tumor necrosis factor-alpha.

\section{Introduction}

Chronic diseases are long-term conditions with slow disease progression and without an effective cure, ${ }^{1}$ and 38 million people die from chronic diseases each year. In addition, 16 million of these deaths occur before the age of 70 years. Chronic diseases may lead to alteration in brain structure and function and are associated with cognitive change..$^{2-5}$ Some of these changes may be related to neurodegenerative diseases (such as Alzheimer's disease and other types of dementia), increased dementia incidence, and cognitive decline. Strategies are needed to reduce disease-related cognitive impairment in chronic disease patients.

Exercise, the aim of which is to improve or maintain physical fitness, is a subset of physical activity that is planned, structured, and flexible, in addition to promoting aerobic endurance. ${ }^{6}$ Exercise is essential in maintaining physical function and physiological health. The results of animal studies have identified that engagement in physical activity may enhance neurotrophic factor levels, ${ }^{7,8}$ neurogenesis, ${ }^{9,10}$ and vascularization ${ }^{11}$ and may even reduce aggregation of pathogenic proteins, ${ }^{12,13}$ mediate neuroinflammation, ${ }^{13}$ and inhibit neuronal dysfunction. ${ }^{14}$ Exercise also appears to be associated with the maintenance of brain health and cognitive performance in cognitively normal older adults. Most experimental studies have identified increased lifetime physical activity to be associated with reduced risk of suffering from dementia in cognitively normal older persons. ${ }^{15-17}$ The results of a meta-analysis of prospective studies on physical activity and the risk of cognitive decline, which included 15 prospective studies (12 cohorts) with 33,816 nondemented subjects followed for 1-12 years, showed that a total of 3,210 patients demonstrated cognitive decline during the follow-up period. The results of the cumulative analysis indicated that subjects who performed high levels of physical activity were significantly less likely to demonstrate cognitive decline during the follow-up period. ${ }^{18}$

The results of a meta-analysis of the effect of physical activity on cognitive function in patients with dementia suggested that physical activity interventions positively influenced cognitive function in patients with dementia. ${ }^{19}$ The results of another meta-analysis of aerobic exercise implied that this practice promotes cognitive function in older adults with mild cognitive impairment, finding that aerobic exercise was associated with an improvement in global cognitive ability. ${ }^{20}$ However, a comprehensive evaluation of the effect of exercise interventions on cognitive function in chronic disease patients has not been conducted. We therefore conducted a meta-analysis and systematic review of randomized controlled trials investigating the effect of exercise intervention on cognitive outcomes in chronic disease patients.

\section{Methods}

\section{Protocol and registration}

The meta-analysis was conducted and reported in accordance with the PRISMA guidelines ${ }^{21}$ to ensure comprehensive and transparent reporting of our methods and results.

\section{Search strategy}

PubMed, Web of Science, Embase, the Cochrane Library, CINAHL, PsycINFO, and three Chinese databases (CNKI, WanFang Data, and VIP) were electronically searched for papers that were published until September 2016. The search strategy included various combinations of the terms "Cognition", "Cognitive function", and "MMSE", with exercise intervention terms such as "Exercise" or "Muscle Stretching Exercises" or "Resistance Training" or "Running" or "Swimming" or "Walking" or "Cycling" or "Physical activity" or "Aerobic" or "Yoga" or "Tai Chi" or "Qigong". Randomized controlled trials were specifically targeted using the following search terms: "Randomized controlled trial", "Controlled clinical trial", or "Randomized" or "Randomly" or "Trial" or "Group". The search was limited to human studies.

\section{Eligibility criteria}

\section{Types of studies}

Only randomized controlled trials were included in this review. No publication date restrictions were imposed on the initial search.

\section{Types of participants}

The participants were adults ( $\geq 18$ years) who had been diagnosed with a chronic disease (eg, arthritis, asthma, cancer, COPD, diabetes, heart disease, or AIDS). ${ }^{1}$ Participants with mental problems were excluded.

\section{Types of interventions}

The inclusion criteria were as follows: 1) the intervention group underwent exercise intervention. When a study included two or more intervention groups that were found to be eligible criteria, we included all in the meta-analysis; 2) the control 
group did not undergo any type of exercise intervention. However, studies in which exercise training was part of an intervention with multiple components (eg, combined with a drug intervention) were excluded.

\section{Types of outcomes}

The studies were required to report global cognitive function as the outcome measure. Any studies reporting only the results for a specific cognition scale, including scales assessing memory, attention, language, verbal fluency, visuospatial ability, or executive ability, were excluded.

\section{Study selection}

The study selection process is outlined in Figure 1. The eligibility assessment was performed by two independent reviewers in a standardized manner. All papers identified using the search strategy were assessed for eligibility, as indicated based on the previously defined inclusion criteria, by reviewing their titles and/or abstracts. If insufficient information was available to evaluate the inclusion or exclusion of an article, then a full-text version was obtained. Full-text versions of all the relevant studies were obtained and reviewed by two independent reviewers to ensure that the studies met the inclusion criteria. Disagreements were resolved by discussion with a third reviewer. When insufficient information or data were available in the included articles, the authors were contacted to obtain additional information if possible.

\section{Quality assessment}

Two reviewers independently assessed the quality of all included studies, using the Downs and Black Quality Index. The scales are designed to assess the methodological quality of randomized studies of health care interventions ${ }^{22}$ and include reporting, external validity, bias, confounding, and power, and their maximum scores are $11,3,7,6$, and 5, respectively. The maximum possible total score is 32 . Quality was then rated on a four-category scale: poor $(<18)$, moderate (18-23), good (24-29), and excellent ( $\geq 30)$.

\section{Data extraction and statistical analysis}

Data were extracted from the included articles using a data extraction form (Table 1). Sample characteristics were collected, including the sample size, intervention and control group sizes, diagnoses, baseline MMSE scores, and age. Details on exercise interventions were collected, including intervention category, frequency, duration, $\mathrm{HR}_{\max }$, and exercise intensity. The effects of the exercise training interventions, including cognitive function measures and the study results, were extracted. One investigator performed the data extraction, which was checked by a second investigator.

The statistical analyses were performed using version 5.3 of the RevMan meta-analysis software. The intervention effect sizes for continuous variables were measured by determining the SMDs between the intervention and control groups with regard to the change observed between the baseline and follow-up cognitive scores and their corresponding 95\% CI. According to the recommendations of the Cochrane Handbook for Systematic Reviews of Interventions, published by Cochrane Collaboration and Wiley, the selection of fixed- or random-effects model is based on the underlying effect of the intervention. ${ }^{23}$ Due to the expected heterogeneity across studies (eg, different intervention types and cognitive outcome measurements), we performed random-effects meta-analysis. Additionally, when the heterogeneity identified across studies was high, a subgroup analysis was performed to identify potential causes of heterogeneity, including exercise types, types of disease, exercise frequency, and intensity. Heterogeneity

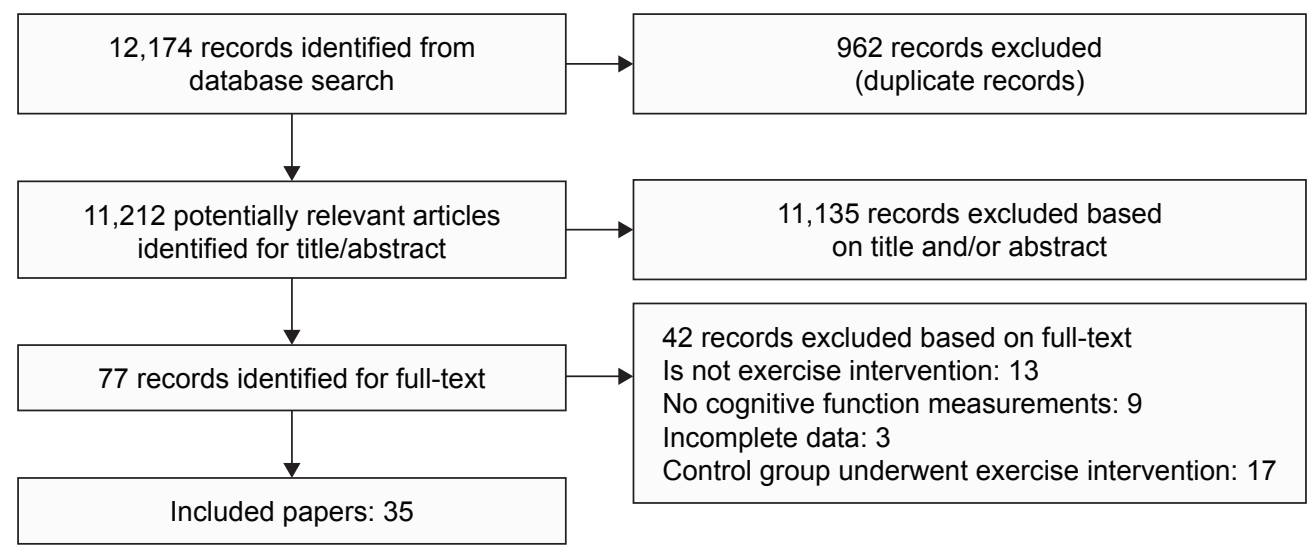

Figure I Flow diagram of literature search. 





was assessed using Higgins $I^{2}$ values. The significance level was set at $P<0.05$.

\section{Results}

\section{Study search and selection}

We identified 12,174 studies based on the database searches; 962 articles were excluded because of duplicate records. Based on title and abstract, we excluded 11,135 studies. The full-text papers of 77 studies were reviewed and 42 studies were excluded. These studies were excluded because they did not assess exercise interventions, reported incomplete data, their control group underwent an exercise intervention, or they did not report cognitive function as an outcome measurement. Finally, 35 studies with 3,113 participants were included in the final analysis (Figure 1). ${ }^{24-58}$

\section{Description of studies}

The characteristics of the included articles are stated in Table 1. In the included studies, the sample size ranged from $20^{24}$ to $278^{37}$ participants. Thirteen studies examined the effect of exercise on cognitive function in patients with Alzheimer's disease. ${ }^{24,25,27,28,30,34,43,46,50,52,54-56}$ Nine studies examined the effect of exercise on cognitive function in patients with mild cognitive impairment. ${ }^{33,37-39,47,48,53,57,58}$ Five studies examined the effect of exercise on cognitive function in patients with cancer. ${ }^{29,35,42,45,49}$ One study examined the effect of exercise on cognitive function in patients with Parkinson's disease. ${ }^{32}$ One study examined the effect of exercise on cognitive function in patients with heart failure. ${ }^{40}$ One study examined the effect of exercise on cognitive function in patients with stroke. ${ }^{41}$ One study examined the effect of exercise on cognitive function in patients with metabolic syndrome. ${ }^{36}$ One study examined the effect of exercise on cognitive function in patients with osteoarthritic knee. ${ }^{44}$ And one study examined the effect of exercise on cognitive function in patients with fibromyalgia. ${ }^{31}$ One study examined the effect of exercise on cognitive function in patients with climacteric syndrome. ${ }^{26}$ The mean baseline MMSE ranged from $5.8^{28}$ to $28.7,{ }^{33}$ excluding 11 studies that did not report baseline MMSE. The mean age ranged from 47.5 years ${ }^{49}$ to 82.5 years. ${ }^{28}$ The interventions were then divided into three exercise modes: aerobic, resistance, and a combination of aerobic and resistance, according to the American College of Sports Medicine. ${ }^{59}$ The frequency of the exercise intervention varied from $40 \mathrm{~min}^{56}$ to $300 \mathrm{~min}^{26}$ per week. The duration of the total training period varied from 6 weeks $^{35,49}$ to 60 weeks. ${ }^{25}$ Fitness level was divided into three modes: low, moderate, and high, according to the American College of Sports Medicine. ${ }^{60}$
Seventeen studies used the MMSE, ${ }^{24,25,27,30,34,37,40,44,47,48 \text {, }}$ 50-54,56,57 three studies used the ADAS-cog, ${ }^{33,38,39}$ three studies used the EORTC questionnaire, ${ }^{42,45,49}$ two studies used the $\mathrm{CDT},{ }^{43,46}$ one study used the $\mathrm{FAB},{ }^{32}$ one study used the ACE-R, ${ }^{41}$ one study used the BOPI- $\operatorname{cog},{ }^{29}$ one study used the BDI-cog, ${ }^{31}$ one study used the PFS- $\operatorname{cog},{ }^{35}$ one study used the FACS, ${ }^{28}$ one study used the SLCT,${ }^{26}$ one study used the MoCA,${ }^{58}$ one study used the ERFC, ${ }^{55}$ and one study used the TCD assessment tool. ${ }^{36}$ These different tools were applied to evaluate the same cognitive domain within a study or between studies.

Among the included studies, three studies compared two intervention types with a control group (Table 1). ${ }^{32,43,51}$

\section{Quality assessment}

Thirty-five studies were included in the quality assessment. The assessment of bias in each domain across the included studies is shown in Table 2. The quality of the majority of the studies was moderate, with a mean score of 22.05. Four studies were rated as of poor quality, 18 studies were deemed to be of moderate quality, and 13 studies were deemed to be of good quality.

\section{Main analysis: effects of exercise intervention on cognitive function}

Thirty-five studies with 3,113 participants evaluated the effect of exercise on cognitive function in patients with chronic diseases. ${ }^{24-58}$ The main analysis revealed a positive overall random effect of the exercise interventions on cognitive function in patients with chronic diseases (Table 3 ).

\section{Secondary analyses} Types of disease

Thirteen studies containing 958 participants examined the effect of exercise on cognitive function in patients with

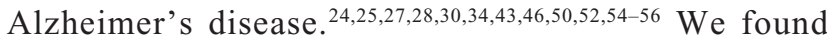
positive overall random effect of exercise intervention on cognitive function in studies evaluating Alzheimer's disease patients. Nine studies containing 1,117 participants examined the effect of exercise on cognitive function in patients with MCI..$^{33,37-39,47,48,51,53,57,58}$ In these studies, the difference observed in postintervention cognitive function did not differ between the exercise group and the control group. Five studies containing 502 participants examined the effect of exercise on cognitive function in patients with cancer. ${ }^{29,35,42,45,49}$ In these studies, the difference observed in postintervention cognitive function did not differ between the exercise group and the control group in cancer patients. 
Table 2 Quality of included studies

\begin{tabular}{|c|c|c|c|c|c|c|c|}
\hline First author (year) & $\begin{array}{l}\text { Reporting } \\
\text { (I I points) }\end{array}$ & $\begin{array}{l}\text { External validity } \\
\text { ( } 3 \text { points) }\end{array}$ & $\begin{array}{l}\text { Bias } \\
\text { (7 points) }\end{array}$ & $\begin{array}{l}\text { Confounding } \\
\text { (6 points) }\end{array}$ & $\begin{array}{l}\text { Power } \\
\text { (5 points) }\end{array}$ & $\begin{array}{l}\text { Total } \\
\text { (32 points) }\end{array}$ & $\begin{array}{l}\text { Quality as per } \\
\text { cutoff described }\end{array}$ \\
\hline Arcoverde $(2013)^{24}$ & 10 & 3 & 6 & 3 & 5 & 27 & Good \\
\hline Oh $(2012)^{42}$ & 10 & 3 & 5 & 3 & 5 & 26 & Good \\
\hline Tsai $(2013)^{44}$ & 8 & 3 & 5 & 3 & 0 & 19 & Moderate \\
\hline Moore $(2015)^{41}$ & 9 & 3 & 6 & I & 5 & 24 & Good \\
\hline Derry $(2015)^{29}$ & 8 & 2 & 5 & 2 & 5 & 17 & Poor \\
\hline Varela $(20 \mathrm{II})^{5 \mathrm{I}}$ & 8 & 3 & 5 & 3 & 0 & 19 & Moderate \\
\hline Hildreth $(2015)^{33}$ & 8 & 2 & 5 & 4 & 0 & 16 & Poor \\
\hline Lindsay $(2014)^{40}$ & 8 & 3 & 5 & 4 & 0 & 20 & Moderate \\
\hline Vadiraja $(2009)^{49}$ & 10 & 2 & 5 & 4 & 0 & 21 & Moderate \\
\hline Schimidt $(2015)^{45}$ & 9 & 3 & 5 & 4 & 0 & 21 & Moderate \\
\hline Gowans $(200 I)^{31}$ & 9 & 3 & 5 & 4 & 5 & 26 & Good \\
\hline $\operatorname{Kim}(2005)^{35}$ & 9 & 2 & 5 & 3 & 0 & 19 & Moderate \\
\hline Ohman $(2016)^{43}$ & 9 & 2 & 5 & 5 & 0 & 21 & Moderate \\
\hline Cancela $(2016)^{25}$ & 9 & 3 & 5 & 4 & 5 & 27 & Good \\
\hline Chattha $(2008)^{26}$ & 9 & 3 & 5 & 3 & 5 & 25 & Good \\
\hline Cheng $(2014)^{27}$ & 9 & 3 & 5 & 4 & 5 & 26 & Good \\
\hline Cott $(2002)^{28}$ & 9 & 2 & 5 & 3 & 0 & 19 & Moderate \\
\hline Christofoletti $(2008)^{54}$ & 7 & 2 & 5 & 2 & 0 & 16 & Poor \\
\hline Hashimoto $(2015)^{32}$ & 9 & 2 & 5 & 1 & 5 & 22 & Moderate \\
\hline Holthoff $(2015)^{34}$ & 9 & 2 & 5 & 2 & 5 & 23 & Moderate \\
\hline $\operatorname{Lam}(2015)^{37}$ & 10 & 2 & 6 & 4 & 0 & 22 & Moderate \\
\hline $\operatorname{Lam}(2012)^{57}$ & 8 & 3 & 5 & 3 & 0 & 19 & Moderate \\
\hline Lautenschlager $(20 \mathrm{I})^{38}$ & 9 & 2 & 5 & 3 & 5 & 24 & Good \\
\hline Lu $(2016)^{39}$ & 9 & 2 & 5 & 3 & 5 & 24 & Good \\
\hline Miu $(2008)^{30}$ & 10 & 2 & 6 & 4 & 5 & 27 & Good \\
\hline Nascimento $(2014)^{58}$ & 8 & 2 & 5 & 2 & 0 & 17 & Poor \\
\hline Kwak $(2008)^{56}$ & 9 & I & 5 & 4 & 5 & 24 & Moderate \\
\hline Kemoun $(2010)^{55}$ & 7 & 3 & 5 & 2 & 5 & 22 & Moderate \\
\hline $\operatorname{Kim}(201 \mathrm{I})^{36}$ & 9 & 3 & 6 & 3 & 5 & 26 & Good \\
\hline Stevens $(2016)^{46}$ & 8 & 2 & 5 & 3 & 0 & 18 & Moderate \\
\hline Suzuki $(2013)^{47}$ & 9 & 2 & 5 & 4 & 0 & 20 & Moderate \\
\hline Suzuki $(2012)^{48}$ & 9 & 2 & 5 & 4 & 5 & 25 & Good \\
\hline $\operatorname{Van}(2004)^{50}$ & 8 & 2 & 5 & 3 & 5 & 23 & Moderate \\
\hline Vreugdenhil $(20 \mathrm{II})^{52}$ & 9 & 3 & 5 & 4 & 5 & 26 & Good \\
\hline Wei $(20 \mid 4)^{53}$ & 7 & 2 & 5 & 2 & 5 & 21 & Moderate \\
\hline
\end{tabular}

Three studies assessed the effect of exercise intervention on cognitive function in patients with osteoarthritic knee, ${ }^{44}$ heart failure, ${ }^{40}$ and metabolic syndrome. ${ }^{36}$ In these studies, the difference observed in postintervention cognitive function did not differ between the exercise and control groups. Four studies evaluated the effect of exercise on cognitive function in patients with fibromyalgia, ${ }^{31}$ stroke, ${ }^{41}$ Parkinson's disease, ${ }^{32}$ and climacteric syndrome, ${ }^{26}$ and the results of these studies indicated that exercise had a positive effect on cognitive function.

\section{Types of exercise intervention}

Twenty-three studies containing 2,120 participants examined the effect of aerobic exercise on cognitive function in patients with chronic disease. ${ }^{24-33,35-37,40,42,44,46,49,51,53,55,57,58}$ Five studies containing 261 participants examined the effect of resistance exercise on cognitive function in patients with chronic disease ${ }^{32,39,41,45,54}$ Eight studies containing 725 participants examined the effect of combined exercise on cognitive function in patients with chronic disease. ${ }^{34,38,43,47,48,50,52,56}$ We identified an overall positive random effect for aerobic exercise interventions but not for resistance exercise interventions and combined exercise interventions. Twenty-seven studies containing 2,845 participants examined the effect of interventions including aerobic exercise (both combined exercise and aerobic exercise intervention) on cognitive function in patient with chronic disease. . $^{24,40,42-44,46-53,55-58} \mathrm{We}$ identified positive overall random effect for the included aerobic exercise interventions.

\section{Frequency of exercise intervention}

According to the World Health Organization recommendations, a weekly schedule of $150 \mathrm{~min}$ exercise was used to distinguish between high- and low-frequency interventions. ${ }^{61}$ 
Table 3 Meta-analysis of effect of exercise on cognitive function

\begin{tabular}{|c|c|c|c|c|c|c|}
\hline Parameters & $\begin{array}{l}\text { Included } \\
\text { studies }\end{array}$ & $\mathbf{N}$ & $P$-value & $I$ & $\mathbf{Z}$ & SMD $(95 \% \mathrm{Cl})$ \\
\hline Main outcome & 35 & 3,113 & 0.0007 & $74 \%$ & 3.41 & $0.26(0.1 I, 0.4 I)$ \\
\hline \multicolumn{7}{|l|}{ Types of disease } \\
\hline Alzheimer's disease & 13 & 958 & 0.004 & $77 \%$ & 2.88 & $0.42(0.14,0.7 I)$ \\
\hline Mild cognitive impairment & 9 & 1,117 & 0.21 & $77 \%$ & 1.25 & $0.17(-0.10,0.44)$ \\
\hline Cancer & 5 & 502 & 0.66 & $86 \%$ & 0.44 & $0.11(-0.39,0.61)$ \\
\hline \multicolumn{7}{|l|}{ Types of exercise intervention } \\
\hline Aerobic & 23 & 2,120 & 0.0008 & $70 \%$ & 3.34 & $0.29(0.12,0.47)$ \\
\hline Resistance & 5 & 261 & 0.69 & $73 \%$ & 0.40 & $0.10(-0.39,0.59)$ \\
\hline Combined & 8 & 725 & 0.14 & $83 \%$ & 1.46 & $0.29(-0.10,0.67)$ \\
\hline Aerobic included & 31 & 2,845 & 0.0005 & $75 \%$ & 3.47 & $0.28(0.12,0.45)$ \\
\hline \multicolumn{7}{|l|}{ Frequency of exercise intervention } \\
\hline High frequency & 18 & I,494 & 0.07 & $83 \%$ & 1.82 & $0.25(-0.02,0.52)$ \\
\hline High frequency (excluded resistance) & 16 & $\mathrm{I}, 450$ & 0.02 & $82 \%$ & 2.24 & $0.31(0.04,0.57)$ \\
\hline Low frequency & 16 & I,547 & 0.0008 & $40 \%$ & 2.67 & $0.19(0.05,0.33)$ \\
\hline Low frequency (excluded resistance) & 14 & 1,409 & 0.15 & $60 \%$ & 1.43 & $0.13(-0.05,0.32)$ \\
\hline \multicolumn{7}{|l|}{ Intensity of exercise intervention } \\
\hline Low & 13 & 1,609 & 0.03 & $77 \%$ & 2.12 & $0.24(0.02,0.47)$ \\
\hline Moderate & 21 & I,322 & 0.03 & $72 \%$ & 2.13 & $0.24(0.02,0.46)$ \\
\hline Moderate (excluded resistance) & 19 & 1,199 & 0.008 & $76 \%$ & 2.66 & $0.34(0.09,0.59)$ \\
\hline High & 2 & 138 & 0.30 & $0 \%$ & 1.04 & $0.18(-0.16,0.51)$ \\
\hline
\end{tabular}

Abbreviations: $\mathrm{Cl}$, confidence interval; SMD, standardized mean difference.

Eighteen studies containing 1,494 participants examined the effect of high-frequency exercise intervention on cognitive function in patients with chronic disease. ${ }^{26-28,33,35,37-40,42,47-50}$ ${ }_{52,54,55,58}$ Sixteen studies containing 1,547 participants examined the effect of low-frequency exercise intervention on cognitive function in patients with chronic disease. . $^{24,25,29-32}$, $34,36,43-46,51,53,56,57$ We identified a positive overall random effect for low-frequency interventions but not for high-frequency interventions. Further investigations revealed that after the exclusion of resistance exercise interventions, the effect of low-frequency exercise interventions was not significant. Further investigations revealed that after the exclusion of resistance interventions, the effect of the high-frequency exercise interventions was significant. Moore et $\mathrm{al}^{41}$ examined the effect of an intervention including 135-180 min of weekly exercise on cognitive function in patients with stroke and found that the exercise intervention did not have an effect on cognitive function.

\section{Intensity of exercise intervention}

Thirteen studies containing 1,609 participants examined the effect of low-intensity exercise intervention on cognitive function in patients with chronic diseases. ${ }^{25-29,35,37,42-44,49,51,57}$ Twenty-one studies containing 1,322 participants examined the effect of moderate-intensity exercise intervention on cognitive function in patients with chronic diseases..$^{24,30-33,}$ 38-40,43,46-48,50-56,58 Two studies containing 138 participants examined the effect of high-intensity exercise intervention on cognitive function in patients with chronic diseases. ${ }^{41,45}$ We found positive random effects for low-intensity and moderate-intensity exercise interventions but not for highintensity exercise interventions. Further investigations revealed that after the exclusion of resistance interventions, the effect of moderate-intensity exercise intervention on the cognitive function was significant.

\section{Discussion}

In this meta-analysis of randomized controlled trials, we identified a positive overall effect of exercise interventions on cognitive function in patients with chronic diseases. Aerobic exercise interventions were found to have a positive effect on cognitive function in patients with chronic disease. In addition, the effect of exercise on cognitive function was independent of the presence of Alzheimer's disease. Furthermore, we found that low-frequency exercise interventions had a positive effect on cognitive function in chronic disease patients. Finally, we observed positive effects of low-intensity and moderate-intensity exercise intervention on cognitive function in chronic disease patients.

In this meta-analysis and systematic review, we found that the exercise interventions were beneficial in the current sample of chronic disease patients. Exercise has been reported to cause physiological state changes that disrupt brain homeostasis. ${ }^{41}$ The brain has been found to modify its resource allocation in response to these changes. Studies have suggested that maintenance of physical activity may 
be associated with increased neural resources in some brain regions and reduced neural resources in other brain regions. ${ }^{47,58,62}$ Exercise affects cognitive function by causing a significant reduction in the peripheral concentrations of IL-6 and $\mathrm{TNF}-\alpha$, as well as a significant increase in peripheral levels of BDNF in individuals with chronic diseases. ${ }^{58}$ Exercise also leads to structural changes in the brain, such as increases in dendritic length and branching and hippocampal neurogenesis, ${ }^{62}$ as well as maintains the atrophy levels of the whole brain cortex. ${ }^{47}$

Cognition is a complex term that includes various domains. Some studies have proposed relationships between specific exercise regimens and specific cognitive domains in chronic disease patients. Aerobic exercise has been reported to contribute to further beneficial effects on the memory domain..$^{32,36,48}$ The results of an animal study investigating the effects of 12 weeks of voluntary running on the restoration of place recognition memory in 20-month-old rats emphasized the unique synaptic effects of exercise on the aged brain and their specific relevance to the hippocampal-based system for place recognition memory. ${ }^{63}$ Dancing involves paying attention to music and signals while envisaging the next movement, and these feature may help patients to perform better in the verbal fluency category. ${ }^{50} \mathrm{Lu}$ et al ${ }^{39}$ found that variations in position changes and movement configurations during dumbbell-training sessions were associated with changes in the spatiotemporal orientation, selective attention, and executive control of participants.

The results of our study showed that aerobic exercise interventions had a positive effect on cognitive function. This result was consistent with the recommendations of the World Health Organization for a weekly minimum of $150 \mathrm{~min}$ of moderate-intensity aerobic or $75 \mathrm{~min}$ of vigorous-intensity aerobic activity with additional musclestrengthening exercises. ${ }^{61}$ Two meta-analyses of the effect of aerobic exercise on cognitive function found that aerobic exercise improved cognitive function. ${ }^{19,20}$ These results were similar to the results of our study. Aerobic exercises improve the maximum oxygen uptake and increase and redistribute cerebral blood flow, enhance antioxidant action via repair enzymes and proinflammatory cytokines, as well as increase beta-amyloid degradation, levels of neurotrophic factors, neurogenesis, and angiogenesis. ${ }^{24,58}$ In this metaanalysis, we did not find resistance exercises to have an effect on cognitive function in chronic disease patients, which may be due to the difficulties related to controlling for some methodological and sampling biases and the short follow-up periods. ${ }^{54}$
In this meta-analysis and systematic review, we found that exercise interventions were beneficial for cognitive function in Alzheimer's disease patients. The results of this study were similar to those of previous studies that reported that exercise has a positive effect on cognitive function in Alzheimer disease patients. ${ }^{19,64,65}$ These trends may indicate that the practice of regular physical exercise might contribute to slower declines in cognitive function. In our study, the exercise interventions were not found to have a positive effect on cognitive function in patients with MCI. There may be insufficient evidence for an effect of exercise intervention on MCI patients. A meta-analysis and systematic review of the effect of aerobic exercise on cognitive function in older adults with MCI showed that aerobic exercise significantly improved global cognitive ability (MMSE scores: $\mathrm{MD}=0.98$, 95\% CI: $0.5-1.45 ; P<0.0001) .{ }^{20}$ The cited meta-analysis and systematic review evaluated interventions encompassing the practice of any aerobic exercises regardless of the style (eg, yoga, Tai Chi, or treadmill) for at least 4 weeks, with $>1$ exercise session per week. In addition, the outcomes assessed included global cognitive ability and any specific domains of cognition assessed in the aforementioned meta-analysis. Our meta-analysis and systematic review was not restricted by type of exercise, and the outcome of interest was global cognitive function. In our study, the exercise intervention was not found to have a positive effect on cognitive function in patients with cancer. The studies that assessed the effects of exercise interventions on cognitive function in cancer patients all provided data for short-term interventions that did not exceed 12 weeks.

In this meta-analysis and systematic review, we found that low-frequency exercise intervention was beneficial in chronic disease patients. The studies providing lowfrequency exercise intervention all exceeded 12 weeks' duration, and two studies even exceeded 48 weeks' duration. ${ }^{25,43}$ The beneficial effect of low-frequency exercise on cognitive function may be associated with a good performance of the functional capacity. ${ }^{24}$ Additionally, all the included studies of low-frequency exercise interventions were of good methodological quality.

The American College of Sports Medicine has suggested that moderate-intensity physical exercise may lead to significant changes in brain health and cognitive performance, with potential effects on a broad range of cognitive domains. ${ }^{66}$ In this meta-analysis and systematic review, we found that both low-intensity and moderate-intensity exercise interventions appeared to be effective in improving cognitive function in chronic disease patients. Moderate-intensity exercise might 
be an effective alternative to reduce the level of systemic inflammation and decrease cognitive decline. ${ }^{58}$ Additionally, most of the studies evaluating moderate-intensity exercise were of good methodological quality. The included studies indicated that low-intensity exercise such as Tai $\mathrm{Chi}^{27,42,44}$ or yoga $^{29}$ exerted positive effects on cognitive function. Patients involved in low-exercise intensity interventions demonstrated more notable changes in physical functioning, contributing to the positive effects observed in psychological well-being. ${ }^{42}$ Lower levels of distress and fatigue may have contributed to the beneficial effects of low-intensity exercise interventions on cognitive function. ${ }^{29}$

\section{Limitations}

This study had some limitations. First, the weekly duration of exercise intervention used in the included studies varied from $40 \mathrm{~min}$ to $300 \mathrm{~min}$ per week, and the overall duration of the exercise intervention used in the included studies varied from 6 weeks to 60 weeks. These differences may have affected the relationship observed between the specific types of exercise and improvements in the evaluated cognitive domains. Second, it was not possible to blind participants to the exercise intervention. Therefore, performance bias may have been unavoidable.

\section{Conclusion}

The findings of this meta-analysis support the efficacy of exercise interventions in improving cognitive function in individuals affected by chronic disease. Beneficial effects were observed independent of the type of clinical disease, type of exercise, frequency, and intensity of the exercise intervention.

\section{Acknowledgment}

This work was supported by the Youth Program of Health and Family Planning Commission of Jilin Province (grant number 2015Q022).

\section{Disclosure}

The authors report no conflicts of interest in this work.

\section{References}

1. Wang C, Collet JP, Lau J. The effect of Tai Chi on health outcomes in patients with chronic conditions: a systematic review. Arch Intern Med. 2004;164(5):493-501

2. Graff-Radford NR. Can aerobic exercise protect against dementia? Alzheimers Res Ther. 2011;3(1):1-6.

3. Kirk-Sanchez NJ, McGough EL. Physical exercise and cognitive performance in the elderly: current perspectives. Clin Interv Aging. 2014;9: $51-62$.
4. Nelson ME, Rejeski WJ, Blair SN, et al; American College of Sports Medicine; American Heart Association. Physical activity and public health in older adults: recommendation from the American College of Sports Medicine and the American Heart Association. Circulation. 2007;116(9):1094-1105.

5. Hess LM, Huang HQ, Hanlon AL, et al. Cognitive function during and six months following chemotherapy for front-line treatment of ovarian, primary peritoneal or fallopian tube cancer: an NRG oncology/gynecologic oncology group study. Gynecol Oncol. 2015;139(3):541-545.

6. Caspersen CJ, Powell KE, Christenson GM. Physical activity, exercise, and physical fitness: definitions and distinctions for health-related research. Public Health Rep. 1985;100(2):126-131.

7. Radak Z, Hart N, Sarga L, et al. Exercise plays a preventive role against Alzheimer's disease. J Alzheimers Dis. 2010;20(3):777-783.

8. Adlard PA, Perreau VM, Pop V, Cotman CW. Voluntary exercise decreases amyloid load in a transgenic model of Alzheimer's disease. J Neurosci. 2005;25(17):4217-4221.

9. Sahay A, Scobie KN, Hill AS, et al. Increasing adult hippocampal neurogenesis is sufficient to improve pattern separation. Nature. 2011; 472(7344):U466-U539.

10. Kronenberg G, Bick-Sander A, Bunk E, Wolf C, Ehninger D, Kempermann G. Physical exercise prevents age-related decline in precursor cell activity in the mouse dentate gyrus. Neurobiol Aging. 2006; 27(10):1505-1513.

11. Ding YH, Luan XD, Li J, et al. Exercise-induced overexpression of angiogenic factors and reduction of ischemia/reperfusion injury in stroke. Curr Neurovasc Res. 2004;1(5):411-420.

12. Leem YH, Lim HJ, Shim SB, Cho JY, Kim BS, Han PL. Repression of tau hyperphosphorylation by chronic endurance exercise in aged transgenic mouse model of tauopathies. J Neurosci Res. 2009;87(11):2561-2570.

13. Belarbi K, Burnouf S, Fernandez-Gomez FJ, et al. Beneficial effects of exercise in a transgenic mouse model of Alzheimer's disease-like tau pathology. Neurobiol Dis. 2011;43(2):486-494.

14. Um HS, Kang EB, Koo JH, et al. Treadmill exercise represses neuronal cell death in an aged transgenic mouse model of Alzheimer's disease. Neurosci Res. 2011;69(2):161-173.

15. Buchman AS, Boyle PA, Yu L, Shah RC, Wilson RS, Bennett DA. Total daily physical activity and the risk of $\mathrm{AD}$ and cognitive decline in older adults. Neurology. 2012;78(17):1323-1329.

16. Hamer M, Chida Y. Physical activity and risk of neurodegenerative disease: a systematic review of prospective evidence. Psychol Med. 2009;39(1):3-11.

17. Scarmeas N, Luchsinger JA, Schupf N, et al. Physical activity, diet, and risk of Alzheimer disease. JAMA. 2009;302(6):627-637.

18. Sofi F, Valecchi D, Bacci D, et al. Physical activity and risk of cognitive decline: a meta-analysis of prospective studies. J Intern Med. 2011; 269(1):107-117.

19. Groot C, Hooghiemstra AM, Raijmakers PG, et al. The effect of physical activity on cognitive function in patients with dementia: a meta-analysis of randomized control trials. Ageing Res Rev. 2016;25:13-23.

20. Zheng G, Xia R, Zhou W, Tao J, Chen L. Aerobic exercise ameliorates cognitive function in older adults with mild cognitive impairment: a systematic review and meta-analysis of randomised controlled trials. Br J Sports Med. 2016;50:1443-1450.

21. Moher D, Liberati A, Tetzlaff J, Altman DG. Preferred reporting items for systematic reviews and meta-analyses: the PRISMA statement. J Clin Epidemiol. 2009;62(10):1006-1012.

22. Downs SH, Black N. The feasibility of creating a checklist for the assessment of the methodological quality both of randomised and nonrandomised studies of healthcare interventions. J Epidemiol Community Health. 1998;52(6):7.

23. Higgins JPT. Cochrane Handbook for Systematic Reviews of Interventions Version. London: The Cochrane Collaboration; 2011.

24. Arcoverde C, Deslandes A, Moraes H, et al. Treadmill training as an augmentation treatment for Alzheimer's disease: a pilot randomized controlled study. Arq Neuropsiquiatr. 2014;72(3):190-196. 
25. Cancela JM, Ayan C, Varela S, Seijo M. Effects of a long-term aerobic exercise intervention on institutionalized patients with dementia. Med Sci Sports Sci. 2016;19(4):293-298.

26. Chattha R, Nagarathna R, Padmalatha V, Nagendra HR. Effect of yoga on cognitive functions in climacteric syndrome: a randomised control study. BJOG. 2008;115(8):991-1000.

27. Cheng ST, Chow PK, Song YQ, et al. Mental and physical activities delay cognitive decline in older persons with dementia. Am J Geriatr Psychiatry. 2014;22(1):63-74.

28. Cott CA, Dawson P, Sidani T, Wells T. The effects of a walking/talking program on communication, ambulation, and functional status in residents with Alzheimer disease. Alzheimer Dis Assoc Disord. 2002;16(2):81-87.

29. Derry HM, Jaremka LM, Bennett JM, et al. Yoga and self-reported cognitive problems in breast cancer survivors: a randomized controlled trial. Psychooncology. 2015;24(8):958-966.

30. DKY Miu SS, Mak YF. A randomised controlled trial on the effect of exercise on physical, cognitive and affective function in dementia subjects. Asian J Gerontol Geriatr. 2008;3:8-16.

31. Gowans SE, deHueck A, Voss S, Silaj A, Abbey SE, Reynolds WJ. Effect of a randomized, controlled trial of exercise on mood and physical function in individuals with fibromyalgia. Arthritis Rheum. 2001; 45(6):519-529.

32. Hashimoto H, Takabatake S, Miyaguchi H, Nakanishi H, Naitou Y. Effects of dance on motor functions, cognitive functions, and mental symptoms of Parkinson's disease: a quasi-randomized pilot trial. Complement Ther Med. 2015;23(2):210-219.

33. Hildreth KL, Van Pelt RE, Moreau KL, et al. Effects of pioglitazone or exercise in older adults with mild cognitive impairment and insulin resistance: a pilot study. Dement Geriatr Cogn Dis Extra. 2015;5(1): $51-63$.

34. Holthoff VA, Marschner K, Scharf M, et al. Effects of physical activity training in patients with Alzheimer's dementia: results of a pilot RCT study. PLoS One. 2015;10(4):e0121478.

35. Kim SD, Kim HS. Effects of a relaxation breathing exercise on fatigue in haemopoietic stem cell transplantation patients. J Clin Nurs. 2005; 14(1):51-55

36. Kim SH, Kim M, Ahn YB, et al. Effect of dance exercise on cognitive function in elderly patients with metabolic syndrome: a pilot study. J Sports Sci Med. 2011;10(4):671-678.

37. Lam LCW, Chan WC, Leung T, Fung AWT, Leung EMF. Would older adults with mild cognitive impairment adhere to and benefit from a structured lifestyle activity intervention to enhance cognition? A cluster randomized controlled trial. PLoS One. 2015;10(3):e0118173.

38. Lautenschlager NT, Cox KL, Flicker L, et al. Effect of physical activity on cognitive function in older adults at risk for Alzheimer disease: a randomized trial. JAMA. 2009;301(3):1027-1037.

39. Lu JJ, Sun MY, Liang LC, Feng Y, Pan XY, Liu Y. Effects of momentum-based dumbbell training on cognitive function in older adults with mild cognitive impairment: a pilot randomized controlled trial. Clin Interv Aging. 2016;11:9-16.

40. Miller LA. The longitudinal effects of cardiac rehabilitation on cognition in older adults with heart failure [dissertation]. Kent: Kent State University; 2014.

41. Moore SA, Hallsworth K, Jakovljevic DG, et al. Effects of community exercise therapy on metabolic, brain, physical, and cognitive function following stroke: a randomized controlled pilot trial. Neurorehabil Neural Repair. 2015;29(7):623-635.

42. Oh B, Butow PN, Mullan BA, et al. Effect of medical Qigong on cognitive function, quality of life, and a biomarker of inflammation in cancer patients: a randomized controlled trial. Support Care Cancer. 2012;20(6):1235-1242.

43. Ohman H, Savikko N, Strandberg TE, et al. Effects of exercise on cognition: the Finnish Alzheimer disease exercise trial: a randomized, controlled trial. J Am Geriatr Soc. 2016;64(4):731-738.

44. Tsai PF, Chang JY, Beck C, Kuo YF, Keefe FJ. A pilot clusterrandomized trial of a 20-Week Tai Chi Program in elders with cognitive impairment and osteoarthritic knee: effects on pain and other health outcomes. J Pain Symptom Manage. 2013;45(4):660-669.
45. Schmidt ME, Wiskemann J, Armbrust P, Schneeweiss A, Ulrich CM, Steindorf K. Effects of resistance exercise on fatigue and quality of life in breast cancer patients undergoing adjuvant chemotherapy: a randomized controlled trial. Int J Cancer. 2015;137(2):471-480.

46. Stevens J, Killeen M. A randomised controlled trial testing the impact of exercise on cognitive symptoms and disability of residents with dementia. Contemp Nurse. 2006;21(1):32-40.

47. Suzuki T, Shimada H, Makizako H, et al. A randomized controlled trial of multicomponent exercise in older adults with mild cognitive impairment. PLoS One. 2013;8(4):e61483.

48. Suzuki T, Shimada H, Makizako H, et al. Effects of multicomponent exercise on cognitive function in older adults with amnestic mild cognitive impairment: a randomized controlled trial. BMC Neurol. 2012;12:128.

49. Vadiraja HS, Rao MR, Nagarathna R, et al. Effects of yoga program on quality of life and affect in early breast cancer patients undergoing adjuvant radiotherapy: a randomized controlled trial. Complement Ther Med. 2009;17(5-6):274-280.

50. Van de Winckel A, Feys H, De Weerdt W, Dom R. Cognitive and behavioural effects of music-based exercises in patients with dementia. Clin Rehabil. 2004;18(3):253-260.

51. Varela S, Ayan C, Cancela JM, Martin V. Effects of two different intensities of aerobic exercise on elderly people with mild cognitive impairment: a randomized pilot study. Clin Rehabil. 2012;26(5):442-450.

52. Vreugdenhil A, Cannell J, Davies A, Razay G. A community-based exercise programme to improve functional ability in people with Alzheimer's disease: a randomized controlled trial. Scand J Caring Sci. 2012;26(1):12-19.

53. Wei XH, Ji LL. Effect of handball training on cognitive ability in elderly with mild cognitive impairment. Neurosci Lett. 2014;566:98-101.

54. Christofoletti G, Oliani MM, Gobbi S, Stella F, Bucken Gobbi LT, Renato Canineu P. A controlled clinical trial on the effects of motor intervention on balance and cognition in institutionalized elderly patients with dementia. Clin Rehabil. 2008;22(7):618-626.

55. Kemoun G, Thibaud M, Roumagne N, et al. Effects of a physical training programme on cognitive function and walking efficiency in elderly persons with dementia. Dement Geriatr Cogn Disord. 2010;29(2): 109-114.

56. Kwak YS, Um SY, Son TG, Kim DJ. Effect of regular exercise on senile dementia patients. Int J Sports Med. 2008;29(6):471-474.

57. Lam LCW, Chau RCM, Wong BML, et al. A 1-year randomized controlled trial comparing mind body exercise (Tai Chi) with stretching and toning exercise on cognitive function in older Chinese adults at risk of cognitive decline. $J$ Am Med Dir Assoc. 2012;13(6): 568.e15-568.e20.

58. Nascimento CMC, Pereira JR, de Andrade LP, et al. Physical exercise in MCI elderly promotes reduction of pro-inflammatory cytokines and improvements on cognition and BDNF peripheral levels. Curr Alzheimer Res. 2014;11(8):799-805.

59. American College of Sports Medicine, Chodzko-Zajko WJ, Proctor DN, et al. American College of Sports Medicine position stand. Exercise and physical activity for older adults. Med Sci Sports Exerc. 2009; 41(7):1510-1530.

60. Thompson PD, Arena R, Riebe D, Pescatello LS. ACSM's new preparticipation health screening recommendations from ACSM's guidelines for exercise testing and prescription, ninth Edition. Curr Sports Med Rep. 2013;12(4):215-217.

61. Organization WH. Global Recommendations on Physical Activity for Health. Geneva: World Health Organization; 2015.

62. Swain RA, Harris AB, Wiener EC, et al. Prolonged exercise induces angiogenesis and increases cerebral blood volume in primary motor cortex of the rat. Neuroscience. 2003;117(4):1037-1046.

63. Siette J, Westbrook RF, Cotman C, et al. Age-specific effects of voluntary exercise on memory and the older brain. Biol Psychiatry. 2013; 73(5):435-442.

64. Farina N, Rusted J, Tabet N. The effect of exercise interventions on cognitive outcome in Alzheimer's disease: a systematic review. Int Psychogeriatr. 2014;26(1):9-18. 
65. Heyn P, Abreu BC, Ottenbacher KJ. The effects of exercise training on elderly persons with cognitive impairment and dementia: a metaanalysis. Arch Phys Med Rehabil. 2004;85(10):1694-1704.
66. American College of Sports Medicine Position Stand. Exercise and physical activity for older adults. Phys Sportsmed. 1999;27(11):115.

\section{Publish your work in this journal}

Clinical Interventions in Aging is an international, peer-reviewed journal focusing on evidence-based reports on the value or lack thereof of treatments intended to prevent or delay the onset of maladaptive correlates of aging in human beings. This journal is indexed on PubMed Central, MedLine,

\section{Dovepress}

CAS, Scopus and the Elsevier Bibliographic databases. The manuscript management system is completely online and includes a very quick and fair peer-review system, which is all easy to use. Visit http://www.dovepress. $\mathrm{com} /$ testimonials.php to read real quotes from published authors. 